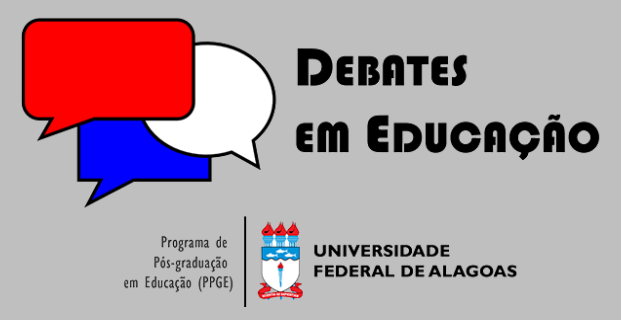

ISSN Eletrônico 2175-6600

Vol. 13 I Número Especial 2 I 2021

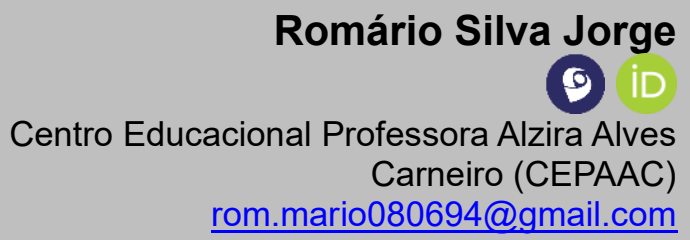

Sônia Maria Alves de Oliveira Reis
Universidade do Estado da Bahia (UNEB)
sonia uneb@hotmail.com

Tatyanne Gomes Marques

(9) iD

Universidade do Estado da Bahia (UNEB) tatygmarques@yahoo.com.br

\section{ESPIRITUALIDADE E RESILIÊNCIA NA PRÁTICA DAS COORDENADORAS PEDAGÓGICAS DE IBITIARA-BA}

\section{RESUMO}

O presente artigo discute sobre os desafios enfrentados pelo/a formador/a de professores/as: o/a coordenador/a pedagógico/a. Promove também uma breve reflexão sobre a espiritualidade, recorrendo aos vários sentidos que lhe foram atribuídos ao longo da história, situando-a enquanto elemento indissociável da identidade profissional. Participaram desta pesquisa seis coordenadoras pedagógicas do município baiano de Ibitiara, na Chapada Diamantina, as quais escreveram um relato pessoal expondo as dificuldades encontradas em sua atuação diária e as estratégias utilizadas para superá-las. Por meio da análise qualitativa dessas produções, à luz de estudos sobre a temática em pauta, constatou-se que, somada aos conhecimentos empíricos e didáticos, a espiritualidade concebe a resiliência necessária para o cumprimento da complexa (por vezes, conflitiva) tarefa de conduzir a formação continuada dos/as professores/as, configurando-se, então, em um aspecto importante para as relações profissionais. Essa discussão abre caminhos para o agenciamento de uma formação integral do sujeito-profissional, tanto na escola quanto na universidade, levando em conta suas múltiplas dimensões sociais.

Palavras-chave: Coordenadoras Pedagógicas; Identidade profissional; Espiritualidade; Resiliência.

\section{SPIRITUALITY AND RESILIENCE IN THE PRACTICE OF PEDAGOGICAL COORDINATORS OF IBITIARA-BA}

\begin{abstract}
This article discusses the challenges faced by the teacher educator/as: the pedagogical coordinator. It also promotes a brief reflection on spirituality, using the various meanings attributed to it throughout history, placing it as an inseparable element of professional identity. Six pedagogical coordinators from the city of Ibitiara, in Chapada Diamantina, participated in this research. They wrote a personal report exposing the difficulties encountered in their daily work and the strategies used to overcome them. Through the qualitative analysis of these productions, in the light of studies on the subject in question, it was found that, added to the empirical and didactic knowledge, spirituality conceives the necessary resilience to fulfill the complex (sometimes conflicting) task of conducting the continuing education of teachers, thus becoming an important aspect for professional relationships. This discussion opens paths for the agency of an integral education of the professional-subject, both at school and at the university, taking into account their multiple social dimensions.
\end{abstract}

Keywords: Pedagogical Coordinators; Professional identity; Spirituality; Resilience.

Submetido em: 29/09/2020

Aceito em: 30/04/2021

Publicado em: 30/11/2021 


\section{Palavras introdutórias}

O/a coordenador/a pedagógico/a (a partir de agora, simplesmente CP) é, sem dúvida, uma pedra angular no processo educativo, porém seu ofício em torno do conhecimento didático, eixo estruturante de seu trabalho, é posto à margem; (des)figurado em virtude das urgências e emergências que minam o contexto escolar. Essa realidade não é diferente daquela vivenciada pelas CPs de Ibitiara, Bahia, Brasil11. Todavia, há um diferencial na forma como lidam com as adversidades, reflexo de um valioso elemento entranhado no seu perfil profissional: a espiritualidade e, por consequência, a resiliência.

Diante dessa brevíssima contextualização, é cogente perpetrar alguns questionamentos basilares: qual é a real função do/a CP na escola? Por que (ainda) é tão difícil exercer a centralidade pedagógica do seu trabalho? De que forma a espiritualidade e a resiliência repercutem em sua atuação cotidiana? Respondê-los é a premissa desta pesquisa $^{2}$, a qual foi nutrida pela revisão da literatura produzida por teóricos que versam sobre a profissão in foco (AMADO et. al., 2012; OLIVEIRA, 2019), educação (FREIRE, 1996; BRANDÃO, 2006; FILLOUX, 2010), espiritualidade, resiliência e suas implicações nas relações educacionais (PAIVA, 2004; FAJARDO; MINAYO; MOREIRA, 2010; GODOY, 2012; SOUZA, 2013).

Por se tratar de vivências e estas serem marcadas pela subjetividade, optamos por analisar, qualitativamente, os relatos pessoais escritos por de seis (6) CPs, considerando suas experiências e histórias de vida para pensar-fazer este estudo (PAULILO, 1999). Por meio desses registros, obtivemos marcas que comprovam as hipóteses levantadas por nós: a espiritualidade e a bagagem vivencial que possuem se desdobra em resiliência, o que thes permite lidar com as situações de cunho pedagógico e os conflitos que afloram nos relacionamentos intra escolares com tranquilidade e perseverança.

Espera-se que este texto ajude o/a leitor/a a conhecer um pouco mais sobre a atuação dos/as CPs, considerando as especificidades do seu ofício. Que, de igual modo, consigam perceber que a espiritualidade está entrelaçada às expressões humanas, inclusive àquelas que acontecem na escola. Assim, conseguirão vislumbrar novas

\footnotetext{
1 Cidade baiana situada no Parque Nacional da Chapada Diamantina, com pouco mais de 15.500 habitantes, segundo dados de 2010 do IBGE. Consulte o site do Instituto para saber mais sobre a cidade: https://cidades.ibge.gov.br/brasil/ba/ibitiara/historico.

2 Vale frisar que esta pesquisa foi desenvolvida no ano de 2018, por isso, é possível que as participantes não estejam mais atuando como coordenadoras pedagógicas, visto que o função ainda é ocupada, na rede municipal de ensino de Ibitiara, através de indicação política. Contudo, as discussões aqui promovidas continuam autênticas, sobretudo, diante dos desafios impostos pela crise sanitária da Covid-19, os quais exigem doses de espiritualidade e sujeitos resilientes.
} 
possibilidades de estudo e pesquisa nos espaços de formação, em Ibitiara e em outros contextos.

\section{A educação escolar na contemporaneidade}

Ninguém escapa da educação. Em casa, na rua, na igreja ou na escola, de um modo ou de muitos, todos nós envolvemos pedaços da vida com ela: para aprender, para ensinar, para aprender-e-ensinar. (BRANDÃO, 2006, p. 7).

Educar é serviço para muitos e, ao mesmo tempo, para poucos. A epígrafe de abertura desta seção evidencia a diversidade de espaços nos quais essa ação pode ser desenvolvida e, implicitamente, os múltiplos agentes que ela envolve: estudantes, pais, professores/as, auxiliares, cidadãos comuns, religiosos ou não. Aqui, há um interesse especial pela educação que acontece nas instituições oficiais de ensino.

A educação escolar é solo fértil para as relações humanas, fermento para a atuação no mundo. É através dela que, segundo Durkheim (1975), o ser individual transforma-se em ser social. É certo que "não há uma forma única nem um único modelo de ensinar; a escola não é o único lugar onde ela acontece e talvez nem seja o melhor". (BRANDÃO, 2006, p. 16). Muitos são os sujeitos que se unem nesse objetivo e, alguns mais, outros menos, se sentem responsáveis por ela.

A educação, "[...] corresponde à necessidade para toda sociedade de assegurar as bases de suas 'condições de existência' e de sua perenidade” (FILLOUX, 2010, p. 16). Acrescenta ainda que, embora opere desde o nascimento, no seio familiar, "é na escola que é sistematizada, de modo que a escola se torna o lugar central da continuidade social, quando se trata da transmissão dos valores, das normas e dos saberes" (FILLOUX, 2010, p. 17). Esse pensamento evidencia o caráter simbólico da instituição escolar para a manutenção das condições de existência da sociedade e enfoca seu papel na perenidade cultural.

Diante disso, nota-se que o ato de ensinar evoca "[...] certa tarefa, certa militância, certa especificidade no seu cumprimento. É um processo que implica o de educar e viceversa, envolve a 'paixão de conhecer' que nos insere numa busca prazerosa, ainda que nada fácil" (FREIRE, 1996, p. 9). Exige de quem nele se entranha muitos conhecimentos, sobretudo, no contexto atual.

A contemporaneidade tem produzido marcas que afetam diretamente as relações sociais e, amplamente, a educação. Nessa direção, ressalta-se que "não somente as 
sociedades mudam, evoluem, têm uma história, mas, no próprio seio dessas sociedades, os sistemas de educação institucionalizados [...] também evoluem e, por sua vez, produzem suas próprias necessidades" (FILLOUX, 2010, p. 16).

Um dos exemplos mais recentes que exprime essa ideia de uma educação em movimento, que reflete e ajusta-se às conjunturas atuais, pode ser traduzido na mobilização para garantir que os/as estudantes continuem aprendendo, diante do isolamento social imposto pela pandemia do novo coronavírus ${ }^{3}$. Essa situação balançou as estruturas educacionais de tal forma que tem feito com que os/as integrantes das comunidades escolares revejam suas práticas e, como muito já foi debatido, procurem integrar a elas o uso das novas tecnologias e das mídias digitais. Devido a essas circunstâncias, o estudo e a relação entre "nativos" e "migrantes"4 têm ocorrido em ambientes virtuais de aprendizagem. Essa tem sido uma saída desafiadora, o que tem feito com que a escola se reinvente integralmente.

É possível levantar várias indagações que exigem mudanças urgentes. Como garantir a equidade no acesso às oportunidades de ensino/aprendizagem diante da avassaladora desigualdade socioeducacional existente? O que fazer para construir um futuro (e um agora!) onde o respeito às diferenças não precise ser reivindicado por meio dos movimentos sociais? Quais sentidos têm essa instituição e até mesmo se o conhecimento ante tamanha fluidez deste tempo? "O que colocamos do mundo, para estudo, nesse tempo e espaço de proteção aos jovens?" (CARVALHO; BERTI, 2018, p. 315). Qual "o significado da instituição escolar em uma organização social que, cada vez mais, deixa de pensar as coisas como comuns a todos?" (CARVALHO; BERTI, 2018, p. 308).

Refletir sobre isso é salutar, pois ajuda a eleger os fios discursivos necessários para a costura de novos horizontes para a educação, "perspectivada como uma atividade humana, centrada nos interesses, motivações e experiências dos sujeitos aprendentes, [...] na natureza subjetiva do conhecimento" (PACHECO et. al., 2018, p. 272).

Diante desse cenário, os/as professores/as e demais agentes que se unem para a tarefa da educação formal notam-se diante de uma indecisão que lhes pesa a consciência: envolver-se com o novo, adotando uma postura mediadora - o que cobrará,

\footnotetext{
${ }^{3}$ Coronavírus é uma família de vírus que causam infecções respiratórias. O novo agente do coronavírus (SARS-CoV-2) foi descoberto em 31 de dezembro de 2019, após casos registrados na China, e provoca a doença chamada de COVID-19.

${ }^{4}$ Prenski (2001) caracteriza os usuários das tecnologias digitais como "nativos" e "migrantes", ressaltando que os/as alunos/as de hoje - do maternal à faculdade - representam as primeiras gerações que cresceram com essa nova tecnologia. Enquanto a maioria dos/as professores/as - pertencentes às gerações anteriores - migraram para essa realidade e a ela tiveram que se adaptar.
} 
obviamente, mais estudo e determinação -, ou permanecer como estão, fazendo com que a escola esmaeça contínua e drasticamente, alheia às constantes transformações que tem ocorrido no mundo (GOES; JORGE, 2021).

Urge conceber não mais educação, mas educações - elas que lidam com situações que vão desde a violência cotidiana às ampliações dos espaços/tempos por intermédio das redes sociais. A união entre sujeitos interdependentes, éticos e criativos, parece ser a grande sacada do momento. Nesse meio, o/a CP tem lugar ainda mais relevante, ajudando os/as professores/as na criação de estratégias para ensinar e tentar resolver os conflitos, buscando a qualidade social da educação. Por isso, seu perfil profissional será o foco da discussão a partir de agora.

\section{Coordenação pedagógica: uma identidade em construção}

Ninguém educa ninguém, ninguém educa a si mesmo, os homens se educam entre si, mediados pelo mundo. (FREIRE, 1996, p. 42).

O discurso do educador pernambucano Paulo Freire (1921-1997) evidencia com precisão a ideia que vigora no que diz respeito à formação continuada para professores/as e à vinculação dessa ação com a prática de um/a profissional muito importante para sua concretização: o/a Coordenador/a Pedagógico/a (CP), mas, afinal, qual é o seu papel na escola? Quais fatores dificultam sua atuação pedagógica? É imperativo refletir sobre estas e outras questões para melhor entendermos os papeis desse/a agente tão importante no universo educacional.

A coordenação e assessoramento pedagógico passaram a ser consideradas atividades educativas, próprias do magistério, pela Lei $\mathrm{n}^{\circ} 11.301$, de 2006 , da Lei de Diretrizes e Bases da Educação Nacional (LDBEN de 1996). Antes disso, como explicitam Amado et. al. (2012), as atribuições desse/a profissional se reduziam à elaboração de atividades burocráticas e distribuição de informações gerais. Segundo as autoras, quando a tríade conhecimento na ação, reflexão na ação e reflexão sobre a reflexão na ação passou a ser o discurso oficial explicitado nas diretrizes de formação em todo o país, é que se começou a consolidar a ideia de que existe uma particularidade e uma especificidade profissional no campo do ensino.

Nesse sentido, aquela realidade em que o/a CP era visto/a como fiscal de atuações educativas, incumbido/a das atividades burocráticas e administrativas, "era vidro e se quebrou"; mas não se quebrou sozinha. Demandou muitos esforços por parte dos/as protagonistas da educação, que lutaram para que a formação continuada estivesse no rol 
das discussões e prioridades nacionais. Assim, ele/a "[...] se coloca como corresponsável pela sala de aula, o trabalho realizado pelo/a professor/a e pela qualidade da aprendizagem dos alunos." (AMADO et al., 2012, p. 28). Além disso,

[...] faz parte do corpo docente e sua função principal vai se dividir entre a formação de professores e a articulação do projeto político-pedagógico. Terá de reconhecer que sua função precípua é a de ser formador e articulador para não se deixar engolir pelas demandas do cotidiano. (AMADO et al., 2012, p. 28).

Assim, formar professores/as é o cerne da sua atuação pedagógica. A (re)construção do conhecimento - quer seja no âmbito da aprendizagem, quer seja no trabalho pedagógico do/a professor/a -, solicita desse/a articulador/a encaminhamentos e conhecimentos a respeito da dinâmica ensino/aprendizagem, oferecendo condições para que ela aconteça potencialmente.

É notório que foram muitas as lutas para instituir a formação continuada como uma condição para que os/as professores/as sigam aprendendo ao longo do exercício profissional. "Torna-se então um direito assegurado e não um benefício a ser oferecido com o intuito de compensar possíveis lacunas da formação inicial” (AMADO et. al., 2012, p. 27). Assim, "entendemos que investigações sobre as condições de trabalho do coordenador pedagógico são fundamentais para subsidiar as lutas em prol da valorização desses profissionais", (OLIVEIRA, 2019, p. 43). Foi esse um dos motivos que nos instigou a escrever o presente artigo.

O/a CP deve estar ciente de suas funções, ou corre o risco de ser tragado pelas demandas do cotidiano, pois muitos são os fatores conflitantes em seu trabalho. Alguns se envolvem em atividades corriqueiras, como atender a telefonemas, apartar brigas e recepcionar as crianças e jovens na escola. Outros, para se sentirem úteis, passam horas do dia planejando e pesquisando atividades que os/as professores/as possam utilizar durante as aulas, adentrando em atuações que não deveriam ser diretamente suas.

Assim, "o trabalho do coordenador vai muito além de ser técnico-administrativo, como muitas vezes é entendido. Trata-se de ação planejada e organizada que implica em objetivos claros e é fator político." (ARRUDA e COLARES, 2016 apud OLIVEIRA, 2019, p. 39). Sem uma rotina bem delineada e um projeto de formação contendo o planejamento cuidadoso das ações que pretende executar, priorizando as necessidades emergenciais do seu grupo, o sentido último da atuação pedagógica se esvai. Percebe-se que, por conta das tímidas e quase inexistentes discussões a respeito de tais assuntos (OLIVEIRA, 
2019), o/a CP possui uma identidade ainda em construção - mas, se construindo, felizmente.

Essa identidade profissional, que tem sua construção marcada pela história da própria função e suas representações, na atualidade, passa pela formação inicial no curso de Graduação em Pedagogia. Todavia, como Souza, Seixas e Marques (2013) mostram, não garante todos os conhecimentos necessários à atuação no âmbito das escolas. As autoras evidenciam, em pesquisa realizada com concluintes do curso de Pedagogia, que o curso deixa a desejar nos aspectos da formação da identidade do profissional de coordenação pedagógica por meio da integração da teoria e da prática, essenciais para o exercício de uma práxis reflexiva. Concluem que "o cargo de Coordenação Pedagógica, tão necessário no ambiente escolar, dispõe de profissionais pouco preparados para exercê-Io" (SOUZA, SEIXAS e MARQUES, 2013, p. 54) e que é, no exercício desse papel, que a identidade profissional do/a CP vai se consolidar. Isto envolve outros fatores, desde os estruturais até aqueles do âmbito mais subjetivo conforme tratamos neste texto.

Salienta-se que "o autoconhecimento - invariavelmente uma construção, não importa o quanto possa parecer uma descoberta - nunca está totalmente dissociado da necessidade de ser conhecido pelos outros". (CASTELLS,1999, p. 22). Esse pensamento é corroborado, ao enfatizar que "o indivíduo só se pode identificar com um papel na medida em que outros o identificam com ele," (BERGER,1985, p. 50), lapidando a imagem de dada profissão enquanto produto social e identitário. Por isso, o/a CP deseja que os/as outros/as percebam e o/a reconheçam, desejo este que faz parte do intento de constituir-se enquanto profissional. Como consequência disso, nas contradições da realidade profissional, precisa mobilizar saberes-fazeres e também suportes espirituais.

Nessa direção, é defendido que: "é preciso formar professores, no entanto, é preciso que essa formação não seja um fim em si mesmo, mas, acima de tudo, uma oportunidade para formar também formadores de professores". (CARDOSO; LERNER; NOGUEIRA; PEREZ, 2014, p. 325). Para isso, é crucial refletir sobre o trabalho que o/a CP faz para identificar aquilo que escapa do seu bojo e, aos poucos, delinear um acompanhamento pontual às suas fragilidades para fortalecê-lo/a. Dessa maneira, é salutar o método de "olhar pelo retrovisor" para explicar os processos ocorridos, procurando entender a tomada de decisão e suas repercussões" (CARDOSO; LERNER; NOGUEIRA; PEREZ, 2014, p. 328), pois, só assim é que se pode fazer bem aquilo que se propõe. 


\subsection{Delineando o perfil das participantes da pesquisa}

Os/as profissionais que batalham em prol da qualidade educacional, na rede municipal de ensino de Ibitiara, Bahia, enfrentam dilemas que perpassam a falta de participação dos pais e a violência na escola, desembocando na fragilidade da aprendizagem e comodismos no que tange às práticas pedagógicas. Contudo, essa rede tem conseguido resultados animadores por meio da formação continuada das supervisoras técnicas ${ }^{5}$, gestores/as, CPs e professores/as, garantida desde o ano 2000, através da parceria firmada entre a Secretaria Municipal de Educação, Cultura, Esporte e Lazer e o ICEP6.

O arcabouço formativo ali presente não blinda tais profissionais contra as angústias e as frustrações que permeiam a sua função. As CPs que forneceram as narrativas aqui analisadas (doravante: Chapada, Nascente, Gruta, Orquídea, Cachoeira e Trilha) ${ }^{7}$ são a prova viva disso. É um grupo constituído por seis (6) professoras advindas de comunidades rurais, com muitos anos de experiência atuando na área, via nomeação política. Todas possuem pós-graduação latu senso: 1 em Gestão Educacional, 3 em Educação Infantil e 2 em Psicopedagogia. Boa parte delas, com exceção das que atuam na sede do município, lida com turmas multisseriadas, o que evoca um acompanhamento sistemático do trabalho dos/as professores/as, no sentido de apoiá-los/as. Essas turmas funcionam em "[...] escolas pequenas, em locais de difícil acesso e conta com baixa densidade populacional; com apenas um professor, todas as séries estudam juntas numa mesma sala de aula". (D’AGOSTINI; TAFFAREL; JÚNIOR, 2012, p. 315).

Externam, como muitos, as dificuldades que possuem, bem como as metas que tentam alcançar, algumas delas frustradas por motivos diversos. No entanto, o diferencial desse grupo está na forma como lida com os fatores oponentes à sua atuação. Independentemente de qualquer elemento constituinte da personalidade, procura estratégias para romper as limitações e alcançar resultados melhores. Dispõe de uma espiritualidade que, entranhada à bagagem teórico-metodológica, parece muni-las de força para encarar os desafios, com coragem e persistência

\footnotetext{
${ }^{5}$ Esses/as profissionais são responsáveis pela formação dos/as coordenadores/as pedagógicos/as e, consequentemente, dos/as professores/as, de acordo com o segmento que atuam no município.

${ }^{6} \mathrm{O}$ Instituto Chapada de Educação e Pesquisa (ICEP) é uma organização sem fins lucrativos, com sede na cidade de Seabra - BA, focada na formação de profissionais da educação, bem como na produção e sistematização de conhecimento na área educacional. Saiba mais sobre o ICEP consultando o site: http://institutochapada.org.br/.

7 Para preservar a identidade das participantes, optamos por utilizar pseudônimos ligados ao campo semântico da Chapada Diamantina, território este do qual elas fazem parte.
} 
Enfim, são mulheres que enfrentam as provações que encontram no ambiente escolar. Por isso mesmo, foram eleitas para colaborar com esta pesquisa, pois o relatar de suas práticas transparece aquilo que aqui se pretende focalizar: a dimensão da espiritualidade. Para que esse pensamento seja esmiuçado, são necessárias algumas notas explicativas sobre a espiritualidade e resiliência, a fim de embasar substancialmente essa discussão.

\section{Notas sobre a espiritualidade e resiliência}

A sociedade na qual vivemos tem um grande desejo pela espiritualidade. Para perceber isso, basta observar a incessante busca das pessoas por um sentido para a vida, as tentativas de preencher uma personalidade aparentemente esvaziada, a procura por religiões e igrejas que, cada vez mais, têm se apresentado em um modelo selfservice, sob uma ótica capitalista - embora o aspecto espiritual não seja uma prerrogativa da experiência religiosa ${ }^{8}$. Nesse ínterim, tamanho interesse "anuncia a possibilidade de um novo olhar sobre o mundo [...]" (TEIXEIRA, 2005, p. 15) e as ações nele desenvolvidas.

Uma pergunta inicial se faz necessária: o que é a espiritualidade? De antemão, cabe salientar que se trata de uma realidade profundamente humana. E o humano, multifacetado e condicionado à sensação de incompletude, carece desse elemento para uma auto superação das suas fraquezas. Ela, por assim dizer, também nasce de um dinamismo intrínseco e está sujeita a diversas (e contraditórias?) interpretações.

Ao longo da história, esse conceito foi desenvolvido a partir de muitas nuances: nasceu dos usos presentes no Primeiro e Segundo Testamento da Bíblia - hálito, espírito (do hebraico "ru'ah") e brisa (do grego "pneuma") -, em conotação a uma vivência da esperança, fé e estado de aceitação/obediência aos Mandamentos de Deus. Entretanto, a palavra em si é utilizada pela primeira vez, em uma carta do século $V$ da era cristã, erroneamente atribuída a São Jerônimo. "Essa carta foi dirigida a um adulto que havia sido batizado recentemente e era exortado a rejeitar uma vida morna e deixar-se tocar pela autêntica vida cristã. Aja de tal maneira que você progrida na espiritualidade", afirma (SOUZA, 2013, p. 132), porém nesse período, a existência espiritual não fazia referência

\footnotetext{
${ }^{8}$ Alguns dados históricos citados neste texto dizem respeito à noção de espiritualidade vivenciada pelos sujeitos da pesquisa, todas elas pertencentes a um universo cristão. No entanto, sabemos que esse aspecto pode ser experimentado nas/pelas religiões e filosofias de vida com outras perspectivas e enfoques.
} 
a um modo pessoal de ser, sendo entendida como a mudança de hábitos, rumo a uma vida nova, tendo como inspiração o agir de Jesus Cristo.

No início da Idade Média, a concepção que se tem de espiritualidade foi permeada por influências filosóficas, que estabeleciam o dualismo entre espírito e matéria, colocando este primeiro como um elemento transcendente ao corpo, no patamar da imortalidade. Durante a Modernidade, a noção de 'espírito' parte desde o imaginário de 'alma racional', passando pela 'capacidade produtiva da razão e sua originalidade', desembocando na 'atitude ou disposição dos indivíduos para fazer algo'.

Do ponto de vista cristão, era concebida como prerrogativa da elite de celibatários monásticos. Os monges escreviam sobre o tema a partir das práticas orantes pessoais. Mais tarde, há um rompimento nessa visão estritamente religiosa, trazendo à tona um campo semântico mais amplo, sucintamente contido no parecer citado a seguir.

Espiritualidade supõe um processo longo de contato consigo e com a vida e seus dilemas e desafios. Não é, portanto, algo mágico e, como uma coisa, adquirível, que entra no mercado das trocas interesseiras. Antes, pelo contrário, é algo da ordem da gratuidade que deve ser cultivada por ela mesma, por seu sentido profundo. (SOUZA, 2013, p. 141).

Portanto, o termo deixa de se concentrar apenas em alguns fenômenos, como os da vida mística, para incluir uma reflexão sobre os valores, as relações, os estilos de vida e as opções pessoais de cada pessoa. Sendo assim, é coerente pensar a espiritualidade sob a ótica da pluralidade, tal como acontece na educação, visto que ela se apresenta em formatos tão diversos quanto os desdobramentos dos experimentos humanos.

Diz respeito a uma dimensão da personalidade dos sujeitos, "[...] que inspira, anima e ajuda a enfrentar os desafios, conferindo-lhe propósitos e significados. Aponta para as experiências mais profundas que dão razão à existência, e propiciam a realização de projetos individuais e coletivos," (ANJOS 2008, p. 19), permeando o imaginário daqueles "[...] que andam em busca de um novo sentido integrador para a vida" (PAIVA, 2004, p. 3).

Nos meandros da educação, parece não haver espaços para discussões que tenham a espiritualidade como centro. Entretanto, há uma série de pesquisas contemporâneas que argumentam a favor de uma educação que contemple a formação integral do sujeito, uma "Educação Transpessoal", como propõe Santos Neto (2001), o que pressupõe considerar suas múltiplas dimensões: corpo, mente, emoção, energia e espírito. A partir dessa perspectiva, defende-se que, "à medida que a Educação visa transformar pessoas no sentido de evoluírem qualitativamente, a espiritualidade trilha o 
mesmo caminho. Portanto, através da espiritualidade educam-se pessoas." (GODOY, 2012, p. 80).

Conforme explica a autora, "o professor pode ajudar seus alunos a vencerem seus medos, suas culpas, ou seja, colaborar para que reconstruam os seus conhecimentos emocionais" (GODOY, 2012, p. 79) de tal forma que possam respeitar a si mesmos e os outros, consequentemente, cuidar da sociedade e do mundo que os acolhe. Não obstante, como assevera a Base Nacional Comum Curricular (BNCC), no contexto do componente curricular do Ensino Religioso, somos convidados a buscar as diferentes formas de expressão da espiritualidade, bem como possibilidades de enfrentamento dos desafios que emanam da convivência humana (BRASIL, 2017).

Com isso, podemos traçar semelhanças entre o conceito de espiritualidade e resiliência, sendo que este último é debatido por Tavares (2001) sob três enfoques correlatos: a) o físico, que remete à resiliência enquanto atributo que possibilita um material retornar à sua forma ou posição inicial, após submetido ao choque e à pressão, por exemplo; b) o médico, relacionado à capacidade que os indivíduos têm de vencer as doenças, por si próprios ou com o auxílio de medicamentos; c) o psicológico, onde a resiliência é a habilidade de as pessoas, individualmente ou em grupo, resistirem às situações adversas sem perder o seu equilíbrio emocional.

Enfim, essa aceitação psicológica do que está fora do controle pessoal, comprometendo-se com ações que melhorem e auxiliem o sujeito no desenvolvimento da sua vida (BARBOSA; MURTA, 2014), pode auxiliar significativamente na descoberta de capacidades, reverberando em sua aceitação e confirmação positiva. Dessa maneira, os sujeitos tornar-se-ão "mais confiantes e resilientes para enfrentar a vida [...] por mais adversa e difícil que se apresente" (TAVARES, 2001, p.52).

Cabe salientar que os atributos da espiritualidade e resiliência podem estar presentes nas instituições de ensino, refletindo em atitudes como: criação de estruturas educativas coerentes e flexíveis, respeito às diferenças, humildade e sensibilidade quanto aos limites individuais e coletivos, comunicação aberta, sentimento de pertença e empatia. Entretanto, a constituição de uma comunidade escolar espirituosa-resiliente demanda formação continuada, bem como uma mudança significativa na forma como essas temáticas de ordem transcendente são acolhidas (FAJARDO; MINAYO; MOREIRA, 2010; GODOY, 2012). Acreditamos que debates como este precisam ganhar mais visibilidade, pois eles nos ajudam a compreender muitos dos paradigmas emergentes com os quais lidamos diariamente na escola e na sociedade de modo geral. 
Postas estas explicações, estabeleceremos o entrecruzamento entre os elementos em foco e o 'eu' profissional, enquanto interfaces que se articulam na formação da identidade e ampliam a probabilidade de sucesso diante dos projetos desenvolvidos no contexto educacional.

\subsection{Profissional Espirituoso-Resiliente: identidades que se cruzam}

Ninguém pode construir uma autoimagem isenta de mudança, de negociação, de transformação em função dos outros. (POLLAK, 1989, p. 18).

Não por acaso, o texto de Pollak (1989) abre esta seção, pois ele mira no alvo da explicitação de um conceito que está sendo (e será!) retomado por diversas vezes nesta discussão: a identidade. Ela que se torna visível na relação entre sujeitos e não é (e nunca foi) imutável. Do ponto de vista sociológico, é possível afirmar que a identidade é construída, à medida em que se convive com outras pessoas, transita por espaços e tece redes.

Ao escrever sobre o tema, na perspectiva do sujeito do campo, Rios (2011) explica que "[...] o ser que fala carrega em si toda uma construção identitária: da roça, da cidade, daqui, dali, de acolá, de um entre-lugar, de um não-lugar ou de todos os lugares juntos". (RIOS, 2011, p. 13). Com este mesmo entendimento, Sá (2011) esclarece que a noção de entre-lugares e não-lugares, atrelada ao imaginário identitário, nos permite pensar a transformação de nós em outros, levando em conta as múltiplas dimensões dos sujeitos, enquanto interfaces coabitantes na identidade.

Diante disso, compreende-se que a espiritualidade é uma manifestação e expressão essencialmente humana, sendo, portanto, indissociável de suas dimensões psicológicas, sociais e afetivas. Trata-se de:

[...] um elemento necessário para o desenvolvimento de muitas das habilidades relacionadas à capacidade de acolher o outro, ouvi-lo, amadurecer as ideias e as posturas, discernir os posicionamentos e valores existentes, avaliar, cultivar a profundidade existencial e das opções fundamentais, centrar-se etc. Ela deve favorecer um diálogo com a existência concreta das pessoas e das sociedades e os desafios presentes nas mesmas. (SOUZA, 2013, p. 139).

Entendida dessa forma, ficam ainda mais nítidas as conexões entre espiritualidade e resiliência, já que esta última tem tudo a ver com presenças significativas, com solidariedade, com interações de seres humanos verdadeiramente humanos que formam 
comunidades saudáveis e acolhedoras (YUNES, 2001). Nota-se que a simbiose espiritualidade-resiliência dialoga precisamente com a atuação do/a CP, visto que faz parte do seu ofício estar atento, apto a ouvir, acolher ideias e avaliar posicionamentos, pois suas ações interferem diretamente no trabalho dos/as professores/as e, consequentemente, na vida de outras pessoas. São essas as qualidades de sua identidade profissional, quase sempre mascaradas, em virtude dos problemas que encontra na escola, da tentativa de resolver todos eles.

Nessa hora, ser resiliente - procurando desenvolver um autoconhecimento, autoaceitação, autorregulação e autoestima, tal como propõe Tavares (2001) -, corrobora para uma compreensão mais estável da tarefa a ser executada, pois "conduz a uma transformação da realidade [...], buscando soluções na prática do cotidiano e uma ampla consciência da vida, dos relacionamentos e do existir" (SOUZA, 2013, p. 140). Logo, a espiritualidade mune o sujeito profissional-espirituoso de bom senso e coragem para enfrentar as tensões com as quais se depara, evoluindo para um pensamento transcendente e resiliente (FAJARDO; MINAYO; MOREIRA, 2010).

$\mathrm{Na}$ escola, as identidades despontam com muita visibilidade. É também o lugar que mais exclui; o que não é uma novidade, visto que "a identidade e a diferença estão em estreita conexão com relações de poder" (SILVA, 2000, p. 77). Diante desse amálgama, a espiritualidade torna-se um dos elementos mais marginalizados. No pódio dos conhecimentos pedagogicamente aceitos, há pouco espaço para aqueles alcançados à luz das religiões, da subjetividade, da emoção ou reflexões mais profundas sobre os dilemas vivenciados pelo ser humano, as quais transitam o meio da espiritualidade, indispensável para o desenvolvimento de posturas resilientes (FAJARDO; MINAYO; MOREIRA, 2010; GODOY, 2012). Os aspectos que extrapolam o bojo pedagógico - não por isso, indissociáveis dele - continuam a ser marginalizados no domínio da educação, tratados com menos valor.

Desse modo, "a atuação dos indivíduos que trabalham na escola, neste caso, as CPs, será tanto mais significativa quanto mais ela estiver em sintonia com os processos sociais que marcam sua trajetória" (SEED/PR, 2008, p. 28), posto que, a expressão do homem "fala mais do que a palavra, porque manifesta inúmeros significados a partir da personalidade" (ARDUINI, 2007, p. 25).

Por isso, a espiritualidade precisa ter maior ênfase no bojo do trabalho pedagógico e ser discutida como um dos elementos para se lidar com os desafios cotidianos, pois, como afirmam Henderson e Milstein (2005 apud FAJARDO; MINAYO; MOREIRA, 2010), ela é importante para o delineamento dos caminhos para a formação de profissionais 
resilientes: "(1) enriquecer os vínculos; (2) determinar limites claros e fortes; (3) ensinar habilidades para a vida; (4) proporcionar afeto e apoio; (5) estabelecer e transmitir expectativas elevadas; (6) proporcionar oportunidades de participação significativa" (p. 763).

No momento em que vivemos, além de tratar sobre metodologias e estratégias didáticas, é imperioso situar o sujeito no centro do processo e ajudá-lo a estabelecer relações produtivas no trabalho, bem como a driblar as angústias provenientes do sentimento de impotência e insucesso ante as ações planejadas.

\section{Relato de práticas, vestígios de espiritualidade e resiliência}

A revisão de literatura feita até aqui permitiu uma compreensão a respeito da temática enfocada neste artigo e, a partir dela, é possível enveredar pela análise dos relatos pessoais das seis (6) CPs de Ibitiara, Bahia. A escrita foi orientada pelo comando "Escreva um relato pessoal contando alguns dos dilemas que você enfrenta em sua atuação cotidiana, enquanto coordenadora pedagógica, explicitando como age diante deles".

Debulhando os registros, nota-se que, para a maioria delas, a profissão é desafiadora, como é perceptível no dizer das CPs Nascente, Orquídea e Cachoeira, respectivamente: "Estar na educação por si já é um enorme desafio, e adentrar uma das pontas de liderança é ainda mais desafiador"; "O trabalho do coordenador é bastante exigente"; "Não considero uma função simples". Essas expressões remetem à responsabilidade que elas têm na escola e como ela se converte em insegurança e preocupações, visto que o seu agir implica diretamente o trabalho dos/as professores/as e a aprendizagem dos/as estudantes.

A visão que muitos dos indivíduos partícipes do processo educativo têm em relação à atuação do/a CP é um dos fatores que contribui para a criação dessa áurea demasiadamente desafiadora. Há aqueles/as que o/a imaginam sempre à disposição, sem objetivos pré-estabelecidos e uma rotina bem delineada, ou seja, sempre disponíveis para resolver as demandas urgentes. Outros/as, enviesados/as por uma ótica histórica, os/as veem como "[...] perseguidores e fiscalizadores" (Nascente). Tomando para si esse ideário reducionista, tais profissionais se encontram perdidas diante do que precisam fazer, à mercê das incompreensões alheias, como deixa claro a CP Cachoeira, quando 
fala que se envolve na "[...] realização de tarefas que não dizem respeito à real função de coordenador."

Os trechos abaixo trazem à tona alguns dos dilemas com os quais se deparam: "[...] internalizar em muitos que uma educação de qualidade pode sim acontecer." (Nascente); "[...] lidar com diferentes sujeitos e concepções.” (Gruta); "[...] a falta de espaço na rotina para momento de estudos pessoais." (Trilha); "[...] as vezes a gente se frustra, principalmente quando monitora o Plano de Formação e vê que não deu para fazer muita coisa." (Chapada).

O primeiro discurso é de ordem social e está fortemente relacionado à ideia de sensibilização e de esperança. "A esperança de que professor e alunos juntos podem aprender, ensinar, inquietar-se, produzir e juntos igualmente resistir aos obstáculos" (FREIRE,1996, p. 72) deve ser o pensamento imperioso na educação. No entanto, sensibilizar os indivíduos para esse envolvimento não é uma tarefa fácil. Como expõe a CP Nascente: "[...] é como sonhar sozinha" - fato este que jamais poderá desmotivar aqueles/as que ainda acreditam na possibilidade de transformação social.

O segundo faz referência à heterogeneidade do grupo com o qual se defrontam, convocando uma abertura à capacidade de escuta, afinal, "[...] existe o outro e ele deve ser respeitado em sua multiplicidade" (CALDART, 2002, p. 74). O terceiro e o quarto discursos tornam explícita a precisão de uma reorganização da rotina de trabalho e do Plano de Formação, pois os estudos de base teórica não podem ser marginalizados em virtude de outras emergências, tampouco restritos a momentos pontuais.

Escrever é imprescindível para aqueles/as que assumem a docência ou a coordenação pedagógica como profissão. "Escreve-se quando se planeja o que será feito, quando se registra o desenvolvimento de algumas aulas para analisá-las com certa distância [...], para compartilhar com outros as propostas que se põem em ação na sala de aula" (LERNER, 2002, p. 205). A leitura teórica, por sua vez, permite uma imersão crítico reflexiva, tendo em mente que, "analisar a prática pela prática, não ajuda a avançar, é preciso teorizá-la”. (AMADO et. al., 2012, p. 89). Desse modo, investir em procedimentos como a escrita profissional e a leitura de textos, são condições para o trabalho das CPs.

A relação com o tempo - ou, como expuseram, a falta dele - é outro fator recorrente, tal como se nota nos trechos a seguir: "Além das cobranças que há no dia-adia da escola, há metas a serem alcançadas e prazos pré-estabelecidos que muitas vezes não dá para cumprir [...]" (Orquídea); “Às vezes parece faltar tempo” (Chapada). Essa aparente falta de tempo desemboca, mais uma vez, na organização do trabalho. Tempo é 
prioridade, por isso, urge percebê-lo como um devir "[...] princípio orientador para a organização das práticas pedagógicas na educação pública." (CARVALHO; BERTI, 2018, p. 313).

Nesse contexto, o grande desafio é listar e estabelecer os conteúdos da formação, esboçando as prioridades com base nos objetivos gerais e nos direitos de aprendizagem dos/as professores/as e estudantes, distribuindo-as no tempo disponível. Como debatido em seções anteriores - e não custa salientar -, "somente quando o/a CP tem clareza de sua função é que ele/a organiza o tempo, de acordo com as obrigações" (AMADO et. al., 2012, p. 85), as especificidades do seu trabalho e o Projeto Pedagógico da escola.

Mesmo cercadas por tantos fatores oponentes ao seu ofício, as CPs demonstram ter uma espiritualidade aguçada, o que as leva a enfrentar esse amálgama a partir de perspectivas transcendentes e graduais, como é notável no relatar de suas práticas: "Procuro não me desesperar diante dos problemas, pois sei que o "lugar" em que estou não permite que o desespero tome conta." (Nascente); "Confesso que o que me faz permanecer são as experiências já vividas com aquelas pessoas, tudo o que já tínhamos conquistado juntos." (Gruta); "[...] no final, tudo dá certo.” (Orquídea); "Espiritualmente, sempre acreditei e acredito que o ser humano é capaz de dar seu melhor." (Trilha).

Os escritos são claros e objetivos. Deles emana o saber experiencial e a tranquilidade que as fazem esperançar, no sentido empregado por Freire (1996), referindo-se à luta para conseguir o esperado, em contraponto à estagnação. Exprimem o desejo que essas profissionais têm de "[...] atingir uma liberdade interior e de encontrar para a vida um sentido que liberta do racionalismo estreito, das concepções tristemente utilitárias" (VERGOTE, 2003, p. 98). A partir dela, as dificuldades se tornam desafios; as angústias se convertem em possibilidades de aprendizado e interação.

A relação com algum tipo de transcendência, que vá além do indivíduo, ou do grupo, ou do tempo/espaço presente, é capaz [...] de conectar a pessoa com totalidades abrangentes, no interior das quais as vicissitudes pessoais ou grupais, temporais ou espaciais, adquirem uma posição mais descentrada. (PAIVA, 2004, p. 6).

Logo, a espiritualidade abstrai os indivíduos e seus grupos, seus afazeres e desafios, ao passo que une realidades cambiantes, enredando-as com doses de resiliência. Estudos feitos comprovam que ela tem contribuído "[...] para a qualidade de vida num sentido corretivo e de fomento" (PAIVA, 2004, p. 10), o que explica o fato de as 
CPs afirmarem que, apesar de tudo, são felizes e gostam do que fazem, transparecendo seu perfil resiliente-espirituoso (GODOY, 2012; FAJARDO; MINAYO; MOREIRA, 2010).

Outra vertente desse atributo empregada por elas foi a religiosidade, recorrendo à história de personagens bíblicos que tiraram de seu sofrimento um aprendizado e assumiram compromissos - o que, nesse contexto, evoca bastante cautela. A presença divina na vida de cada uma parece ser tão íntima e constante, que tudo mais se torna relativo, no sentido positivo do termo.

"Recorro a estudos teóricos para sustentar minhas ideias, mas também à espiritualidade [...] na história de Jó, da Bíblia, que diante de todas as peças, em nenhum momento deixou de acreditar que iria conseguir." (Nascente).

"A fé em Deus nos ajuda a prosseguir sempre, em qualquer situação." (Gruta).

"Busco sempre esse refúgio espiritual que me acalma e me faz ter uma visão mais abrangente das coisas, pensar com mais clareza [...]" (Orquídea).

"[...] jamais poderia me esquecer de que eu só conseguirei executá-lo a contento se eu estiver alicerçada na palavra de Deus [...] afinal, tudo é possível ao que crê." (Cachoeira).

"Quem tem paz, vê as adversidades e não se deixa abater [...] com fé e persistência, aos poucos, conseguimos." (Chapada).

Desses relatos, emergem alguns pontos importantes. Em princípio, fica latente que o dado espiritual e religioso pode estimular atitudes perseverantes. Paiva (2004, p. 9) explica que, "[...] no que tange aos valores, espiritualidade e religião coincidem no cuidado com o outro e com o respeito do outro na expansão do eu". (PAIVA, 2004, p. 9). Berger acrescenta que "[...] a religião mantém a realidade do mundo socialmente construído no qual os homens existem nas suas vidas cotidianas", (BERGER, 1985, p.35) permitindo que a ordem e sentidos existenciais permaneçam legítimos.

No entanto, é necessário problematizar o conteúdo da fé e a menção ao nome de Deus que, implícita e explicitamente, neles sobressaem. É fato que os valores religiosos estão entrelaçados à personalidade e, de alguma forma, promovem crescimento pessoal, porém, essa exposição em escolas públicas, aparelhos do Estado, vai de encontro ao princípio da laicidade preconizado pela Constituição Cidadã de 1988 e documentos oficiais da educação. Nesse caso, aconselha-se que tais posturas sejam revistas, evitando uma relação dogmatizante entre educação e religião, ou restringir a noção de 
espiritualidade ao campo semântico do sagrado, o que destoa do direcionamento apontado neste trabalho.

Por tudo isso, percebe-se que as imbricações (e os reflexos) da espiritualidade e resiliência no fazer educativo precisam ser refletidas com mais vigor no campo científico, especialmente, na educação, dada a sua relevância enquanto elemento constituinte da identidade dos sujeitos. Afinal, elas são fundamentais para que as pessoas encontrem sentido na sua existência e no seu exercício profissional (GODOY, 2012), tornando-se cada vez mais resilientes, enfim, cidadãs melhores (FAJARDO; MINAYO; MOREIRA, 2010).

Destarte, cabe frisar que "a existência humana é essencial e inevitavelmente uma atividade exteriorizante" (BERGER, 1985, p. 40). Portanto, suas expressões exercem significativa influência sobre tudo o que fazem, respingando, inclusive, no planejamento de uma educação mais humanizada, centrada na formação integral dos sujeitos, tal como nos lembram os documentos oficiais da educação e os/as autores/as da literatura consultados/as por nós na tessitura deste artigo.

\section{Considerações finais}

Realizar esta pesquisa foi uma tarefa gratificante, pois significou o alcançar de um grande objetivo: mostrar que a espiritualidade e a resiliência se manifestam em todas as esferas da vida humana, inclusive no trabalho, por isso, precisam ser refletidas nos espaços formativos. Afinal, se precisamos pensar na formação integral do sujeito, considerando suas múltiplas dimensões, tal como sugere a BNCC (BRASIL, 2017), é cogente pensar percursos formativos por meio dos quais professores/as e CPs possam ir se construindo como educadores/as que detêm fatores como a espiritualidade e resiliência (FAJARDO; MINAYO; MOREIRA, 2010), fundamentais para a instauração de uma comunidade escolar resistente às adversidades.

No desenvolvimento do presente estudo, apoiamo-nos na atuação das CPs do município de Ibitiara, Bahia, de modo que explicitamos a relevância do seu perfil profissional-espirituoso-resiliente no trato das questões de cunho pedagógico. Com isso, espera-se que novos horizontes possam se abrir no campo da formação de educadores/as, na educação básica e na academia, contribuindo para a articulação entre áreas do conhecimento (Educação, Antropologia, Psicologia...) e a qualidade das relações profissionais. 
Enfim, com este estudo, ressalta-se a necessidade de agenciar a formação continuada para formadores/as de professores/as. Constatamos, ainda, que a espiritualidade é uma expressão identitária das CPs e, como tal, não pode ser desvencilhada das suas vivências profissionais. Justamente por isso, elas demonstram ter tanta sensibilidade na atuação cotidiana, encarando os desafios com resiliência, consequentemente, contribuindo para o alcance da qualidade educacional no município.

\section{REFERÊNCIAS}

ANJOS, M. F. Para compreender a espiritualidade em bioética. São Paulo: Paulinas, Centro Universitário São Camilo, 2008.

ARDUINI, J. Ética responsável e criativa. São Paulo: Paulus, 2007.

BARBOSA, L. M.; MURTA, S. G. Terapia de aceitação e compromisso: história, fundamentos, modelo e evidências. Revista Brasileira de Terapia Comportamental e Cognitiva, 16(3), pp. 34-49. Disponível em:

http://rbtcc.webhostusp.sti.usp.br/index.php/RBTCC/article/view/711. Acesso em: 24 abr. 2021.

BERGER, P. L. O dossel sagrado: elementos para uma teoria sociológica da religião. São Paulo: Paulinas, 1985.

BRANDÃO, C. R. O que é educação. São Paulo: Brasiliense, 2006.

BRASIL. Lei 9394, de 1996. Diário Oficial da União, Brasília, DF, 1996. Disponível em: http://www.planalto.gov.br/ccivil 03/leis/19394.htm. Acesso em: 26 abr. 2020.

BRASIL. Lei n 11.301, de 2006. Diário Oficial da União, Brasília, DF, 2006. Disponível em: http://www.planalto.gov.br/ccivil 03/ ato2004-2006/2006/lei//11301.htm. Acesso em: 27 abr. 2021.

BRASIL. Base Nacional Comum Curricular. Brasília: MEC, 2017. Disponível em: http://basenacionalcomum.mec.gov.br/images/BNCC El EF 110518 versaofinal site.pdf Acesso em: 27 abr. 2021.

CALDART, R. S. Por uma Educação do Campo: traços de uma identidade em construção. Brasília: ANPUEC, 2002.

CARDOSO, B; LERNER, D.; NOGUEIRA, N.; PEREZ, T. (Org.). Ensinar: tarefa para profissionais. Rio de Janeiro: Record, 2007.

CARVALHO, R. M. de A; BERTI, A. O. O tempo na educação pública: ensaio a partir do movimento "ocupa tudo". Educação Unisinos, São Leopoldo/RS, v. 22, n. 4, outubro/dezembro 2018. Disponível em:

http://revistas.unisinos.br/index.php/educacao/article/view/edu.2018.224.08. Acesso em: 20 abr. de 2020 
CASTELLS, Manuel. A sociedade em rede. São Paulo: Paz e Terra, 1999.

D' AGOSTINI, A; TAFFAREL, C. Z; JÚNIOR, C. de L. dos S. "Escola Ativa". In: CALDART, R. S; PEREIRA, I. B; ALENTEJANO, P; FRIGOTTO, G. (org.). Dicionário da Educação do Campo. Rio de Janeiro, São Paulo: Escola Politécnica de Saúde Joaquim Venâncio, Expressão Popular, 2012.

DE SOUZA, F. J.; SEIXAS, G. O.; MARQUES, T. G. O coordenador pedagógico e sua identidade profissional. Práxis Educacional, [S. I.], v. 9, n. 15, p. 39-56, 2013. Disponível em: https://periodicos2.uesb.br/index.php/praxis/article/view/747. Acesso em: 28 abr. 2021.

DURKHEIM, E. Educação e sociologia. São Paulo: Edições Melhoramentos, 1975.

FAJARDO, I. N; MINAYO, M. C. S; MOREIRA, C. O. F. Educação escolar e resiliência: política de educação e a prática docente em meios adversos. Ensaio: Avaliação e

Políticas Públicas em Educação. Rio de Janeiro, v. 18, n. 69, out./dez. 2010, pp. 761774. Disponível em: https://www.scielo.br/scielo.php?pid=S0104-

40362010000400006\&script=sci arttext\&tlng=pt. Acesso em: 24 abr. 2021.

FILLOUX, J. C. Émile Durkheim. Recife: Editora Massangana, 2010.

FREIRE, P. Pedagogia da Autonomia: saberes necessários à prática educativa. São Paulo: Paz e Terra, 1996.

GODOY, H. P. Proposta de uma educação para a espiritualidade. Interdisciplinaridade, São Paulo, v.1, n. 2, out. 2012, pp. 72-83. Disponível em:

https://revistas.pucsp.br/index.php/interdisciplinaridade/article/view/16245. Acesso em: 24 abr. de 2021.

GOES, B. O. S.; JORGE, R. S. Juventude Conectada: uma experiência de protagonismo juvenil através das mídias digitais. In: Anais do I Simpósio Internacional Juventudes e Educação: Cenários educacionais em tempos de reformas. Juazeiro(BA) Complexo multieventos - Virtual, 2020. Disponível em:

https://www.even3.com.br/anais/sinjuve/248688-juventude-conectada--uma-experienciade-protagonismo-juvenil-atraves-das-midias-digitais/. Acesso em: 28 abr. de 2021.

IBGE. Censo Demográfico. Microdados, 2010. Disponível em:

https://cidades.ibge.gov.br/brasil/ba/ibitiara/panorama. Acesso em: 27 abr. 2021.

AMADO, C; INOUE, A. (coordenação geral); GOUVEIA, B. (coordenação pedagógica), MONTEIRO, E. [et al.] (elaboração). Coordenador Pedagógico: Função, Rotina e Prática. Educar em Rede. Palmeiras: Instituto Chapada de Educação e Pesquisa, 2012.

LERNER, D. Ler e escrever na escola: o real, o possível e o necessário. Porto alegre: Artmed, 2002.

OLIVEIRA, E. G. de. As condições de trabalho do coordenador pedagógico no território sertão produtivo da Bahia. (Dissertação mestrado) - Universidade Estadual do Sudoeste 
da Bahia, Programa de Pós-Graduação em Educação - PPGED, Vitória da Conquista, 2019.

PACHECO, J. A; MENDES, G. M. L; SOUZA, J. R. F. de. O conhecimento escolar em tempos de uma pluralidade de saberes e novas formas de aprendizagem. Educação Unisinos, São Leopoldo/RS, v. 22, n. 4, pp. 268-277, out./dez. 2018. Disponível em: http://revistas.unisinos.br/index.php/educacao/article/view/edu.2018.224.04. Acesso em: 20 abr. 2020.

PAIVA, G. J. de. Espiritualidade e qualidade de vida: pesquisas em psicologia. Porto Alegre: Edipucrs, 2004.

PARANÁ. Secretaria de Estado da Educação. Cadernos Temáticos: Educação do Campo. Curitiba: SEED-PR, 2008.

PAULILO, M. A. S. A pesquisa qualitativa e a história de vida. Serviço Social em Revista, Londrina, v. 2, n. 2, jul./dez. 1999, pp., p.135-148. Disponível em: https://www.uel.br/revistas/ssrevista/c-v2n1.htm. Acesso em: 28 abr. 2021.

POLLAK, M. Memória, Esquecimento, Silêncio. Rio de Janeiro: Jorge Zahar, 1989.

PRENSKY, M. Aprendizagem baseada em jogos digitais. São Paulo: Senac, 2001.

RIOS, J. A. V. P. Ser e não ser da roça, eis a questão! Identidades e discursos na escola. Salvador: EDUFBA, 2011.

SÁ, T. Lugares e não lugares em Marc Augé. Tempo Social, v. 26, n. 2, 2014, pp. 209229. Disponível em: https://www.revistas.usp.br/ts/article/view/97978. Acesso em: 24 abr. 2021.

SANTOS NETO, E. dos. Por uma Educação transpessoal: a ação pedagógica e o pensamento de Stanislav Grof. São Paulo: Metodista; 2006.

SILVA, T. T. da. Identidade e diferença: a perspectiva dos estudos culturais. Petrópolis: Vozes, 2000.

SOUZA, C. F. B. de. Espiritualidade e bioética. Revista Pistis Praxis, Curitiba, v. 5, n. 1, jan./jun. 2013, pp. 123-145. Disponível em:

https://periodicos.pucpr.br/index.php/pistispraxis/article/view/8690. Acesso em: 24 fev. de 2021.

TAVARES, J. A resiliência na sociedade emergente. IN: TAVARES, J. (org.). Resiliência e educação. São Paulo: Cortez, 2001, pp.43-76.

TEIXEIRA, F. O potencial libertador da espiritualidade e da experiência religiosa. São Paulo: Paulus, 2005.

VERGOTE, A. La théologie devant les changements culturels en Europe. Paris: Cerf, 2003.

YUNES, M. M. Resiliência: noção, conceitos afins e considerações críticas. In: TAVARES, J. (Org.). Resiliência e educação. São Paulo: Cortez, 2001. 